\title{
In vivo nutritive value of rice feed for sheep and its application for cattle feed
}

\author{
Ji Yung Kim¹, Bae Hun Lee ${ }^{1}$, Befekadu Chemere ${ }^{1}$, Doo Hong Min², Byong Wan Kim¹ and Kyung II Sung ${ }^{1 *}$ \\ ${ }^{1}$ Department of Animal Life Science, Kangwon National University, Chuncheon 24341, Korea \\ ${ }^{2}$ Department of Agronomy, Kansas State University, Manhattan, KS 66506, USA
}

\begin{abstract}
The objective of this study was to evaluate the nutritive value of polished rice (PR) vs unpolished rice (UPR) as a potential feedstuff for sheep in order to use as a replacer to corn in sheep diet, and as well as to present the application in the formulation of cattle diet. Six corriedale ewe were randomly assigned to each treatment. UPR and PR were provided as a dietary treatment together with timothy grass as a basal diet in a crossover design for two period with 15-d duration for each period. The ratio of experimental and basal feeds were $33.3 \%$ and $66.7 \%$, respectively. The differences in the total digestible nutrient (TDN) contents between sheep and cattle was determined according to the references. The number of data collected sheep and cattle was 9 and 17, respectively. The PR showed higher nutrients digestibility than UPR. Similarly, higher TDN content was observed PR than UPR $(p<0.05)$. As a result, the replacement of corn in the formulate feed with UPR and PR feed rice could be possible with the ratio of $91.2 \%$ and $100.0 \%$, respectively. The result of comparation the TDN contents of UPR and PR in sheep and cattle, the PR has no difference in the nutritive value which suggests the applicability of the results of sheep to cattle. On the other hand, UPR has known to have different nutritive value between sheep and cattle, so caution should be taken when preparing formula feeds for cattle.
\end{abstract}

Keywords: Rice feed, Unpolished rice, Polished rice, Sheep, Cattle, Total digestible nutrient

\section{Background}

The surplus production together with a decrease in public consumption led to increase the amount of stocked rice in the country. According to Korean Rural Economic Institute [1], the national stock reached about 1.89 million tons in 2017, which is twice as much as the recommended stock level [2]. In addition, the annual management cost per 10,000 tons of stock is 3,600 million won and the total management cost is estimated to be 670 billion won [3]. To reduce high stocks of rice, the government released rice to be used as a feed for the first time in 2015-2016, making 101,000 tons of brown rice available for feed use [4]. In 2016-17, 480,000 ton of brown rice was released for feed use and the government recently announced a plan to release 750,000 tons in 2017-18 [5]. Therefore, considering a continued government policy encouraging the use of old rice for animal feed, it is necessary to evaluate the potential utilization of polished rice (PR) in the diet of livestock.

On the other hand, as Republic of Korea is mainly dependent on imported feed resources for livestock feed [6], replacing some of the feed resources like corn with rice in the ration has big economic significance. Whereas in recent years, human consumption of corn has been expanding rapidly, leading to inadequate supplies and high prices. This necessitates the search for alternative feed sources to grains such as corn in the diet of livestock.

In Japan, several researches on the utilization of rice as feed source together with the processing methods such as crushing and 
steam flaking, and also manuals on the inclusion rate in the rations of dairy cows has been reported [7]. The processing methods of unpolished rice (UPR) uses feed size of less than $2 \mathrm{~mm}$, and up to $40 \%$ inclusion rate reported to be beneficial. On the other hand, since the additional cost is needed for processing of rice feed that to be used for livestock feed, the use of UPR believed to reduce the processing cost that has been used for rice feed. Meanwhile in Korea, even though there were studies on the utilization of rice feed for livestock $[8,9]$, so far no research report has been indicated on the utilization of UPR as livestock feed. Despite similarity in the digestive system between sheep and cattle, nutrient digestibility of grain tends to be higher in sheep than in cattle, but forage digestibility is higher in cattle [10]. However, there are fewer diet evaluation systems for sheep and biologically more empirical than the cattle systems [11]. Thus, as total digestible nutrient (TDN) values represent utilizable energy contents of feedstuffs, and are important values in order to provide adequate energy supply for livestock [12]. In addition, since the TDN content would be a more reliable measure of the dry matter consumed, it is necessary to confirm whether the several results of the sheep's nutrient digestibility and TDN content (nutritive value) were applicable for cattle, as the calculation of their nutritive value is easier than that of cattle in terms of livestock management and cost. This study was aimed to evaluate the nutrients digestibility and TDN content of UPR and PR in sheep for a potential replacement of corn grain, and as well as to present the applicability in the formulation of cattle diet.

\section{Materials and Methods}

\section{Nutritive value of the UPR and PR in the sheep}

This experiment was carried out in accordance with the animal care and use policy of Kangwon National University, Chuncheon, Republic of Korea. It was conducted at Kangwon National University farm, Chuncheon, Kangwon Province.

Rice was used as a dietary treatment and classified in to two groups of UPR and PR along with timothy hay which was used as basal feed in the experiment and fed based on their maintenance requirement [13]. The experimental animals were six corriedale ewe (ave. BW $=47.2 \pm 7.7 \mathrm{~kg}$ and 3-year-old), and were randomly assigned into two groups of three sheep and two treatments were applied in $2 \times 2$ crossover design over 30 day's period. The ratio of experimental feeds and basal feeds were $33.3 \%$ and $66.7 \%$, respectively and water was provided free of choice. The experiment was started with 5 days of preliminary period followed by 5 days of adaptation period, and 5 days of sample collection period. The preliminary period was applied to test the ewe with lower amount of proposed diets before applying the actual amount during the adaptation period. This was to make sure that no drawbacks associated with feeding of PR and UPR. The feed was provided in the morning at 08:00 and afternoon at 18:30. During the experimental period, sample feces were obtained by total collection method twice a day at 08:00 and 18:00. Then, sample feces were oven dried at $60^{\circ} \mathrm{C}$ for 72 hours and the dried samples were milled using $20 \mathrm{~mm}$ meshing, and stored in a place where there was no contact with sunshine. The experimental feeds were analyzed for crude ash (Ash), crude protein $(\mathrm{CP})$, ether extracts $(\mathrm{EE})$, crude fiber $(\mathrm{CF})$ and nitrogen free extract (NFE) were analyzed by AOAC [14] method, and neutral detergent fiber (NDF) and acid detergent fiber (ADF) contents on dry matter (DM) basis according to Goering and Van Soest [15].

The feed intake was calculated by subtracting the residual from the feed offered, whereas the nutrient digestibility was calculated by subtracting the nutrient content in the feces from the feed offered. The undigested experimental feed grain in feces was calculated from the ratio of undigested UPR and PR grain in feces to the number of UPR and PR grain offered, respectively, multiplied by 100. To do so, the number of undigested grains in $10 \mathrm{~g}$ of sample feces was determined by soaking in the water followed by meshing. Then, the total undigested grain determined from the whole feces. The TDN content was calculated on the basis of nutrient digestibility between experimental and basal feeds. The TDN content was calculated by the following equation [16]:

$$
\mathrm{TDN}=\mathrm{DCP}(\%)+\mathrm{DCF}(\%)+\mathrm{DNFE}(\%)+2.25 \times \mathrm{DEE}(\%)
$$

Where, DCP, digestible crude protein; DCF, digestible crude fiber; DNFE, digestible nitrogen free extraction; DEE, digestible ether extraction.

\section{Application of UPR and PR for cattle feed}

The differences in the TDN contents between sheep and cattle was determined according to the references from Han [17], Korean Feed Information Center [18], NRC for Dairy [16,19,20], NRC for sheep [21-23], the Japanese specification standard (cow, [24]) and Macgregor [25] and confirmed through statistical analysis. The collected TDN contents data was used with clearly specified livestock that sheep and cattle in the reference. The number of data collected sheep and cattle was 3 and 7 in the UPR, as well as 6 and 10 in the PR, respectively.

\section{Statistical analysis}

Statistical analysis was performed using SPSS 22.0 [26]. The significance test of experiment data and the difference on collected TDN contents data of UPR and PR in the examined sheep and cattle were examined by independent samples $t$-test. 


\section{Results and Discussion}

\section{Nutritive value of the UPR and PR in the sheep}

The DM, OM, and EE contents in the two groups were comparable (Table 1). However, the $\mathrm{CP}, \mathrm{NFE}$, and $\mathrm{CF}$ contents in $\mathrm{PR}$ were higher than in UPR $(p<0.05)$. On the other hand, the fiber fractions were lower in PR than in UPR $(p<0.05)$, which is in line with NRC [16] that rice hull constitutes $42.9 \%, 82.0 \%$, and $72.0 \%$, of CF, NDF, and ADF, respectively. This also indicates as the hull part constitutes most of the fiber fractions in rice. Similar tendencies were observed in unpolished and brown rice [7].

There were no significant differences between UPR and PR in terms of CP and EE digestibility $(p>0.05)$, despite a tendency for PR to be significant (Fig. 1). The digestibility of NFE and CF were

Table 1. Chemical composition of experimental feeds

\begin{tabular}{lcc}
\hline \multicolumn{1}{c}{ Item } & UPR & PR \\
\hline DM $(\%)$ & 89.6 & 89.0 \\
OM $(\%$ of DM) & $95.6 \pm 0.3$ & $98.4 \pm 0.1$ \\
CP $(\%$ of DM) & $8.5 \pm 0.2$ & $9.6 \pm 0.3$ \\
EE $(\%$ of DM) & $3.0 \pm 0.2$ & $2.9 \pm 0.2$ \\
NFE $(\%$ of DM) & $73.9 \pm 1.3$ & $85.9 \pm 0.2$ \\
CF $(\%$ of DM) & $10.2 \pm 1.1$ & $0.1 \pm 0.0$ \\
NDF $(\%$ of DM) & $27.6 \pm 4.3$ & $8.3 \pm 0.1$ \\
ADF $(\%$ of DM) & $16.6 \pm 1.2$ & $1.7 \pm 0.2$ \\
\hline
\end{tabular}

UPR, unpolished rice; PR, polished rice; DM, dry matter; OM, organic matter ( $=100-$ ash); $\mathrm{CP}$, crude protein; $\mathrm{EE}$, ether extracts; $\mathrm{NFE}$, nitrogen free extract; $\mathrm{CF}$, crude fiber; NDF, neutral detergent fiber; ADF, acid detergent fiber. found to be higher in PR $(p<0.05)$. Similarly, higher TDN content was observed in PR than in UPR $(p<0.05)$. The difference in the nutrient digestibility of UPR and PR is thought to be due to the presence of hull in UPR. According to Charles [27] and McDonald et al. [10], NDF, ADF, lignin and silica contents of rice hulls were $82.0 \%, 72.0 \%, 16.0 \%$, and $21.0 \%$, respectively. These are important constituents that affect the digestibility of feed, especially in small ruminants like sheep. Because cows had better digestion compared with sheep due to the longer retention time of low-quality feeds in the rumen [28], that means fiber fraction including undigestible components sensitively was effected on digestibility of sheep. In Republic of Korea, the National Livestock Research Institute [29] reported that NDF, ADF, lignin and silica content of rice straw were $75.4 \%, 51.0 \%$, 5.9\%, and 8.0\%, respectively. These results indicate the higher fiber fraction was presented in the hull than in the straw portion of rice that led to a decrease in the digestibility in sheep. Our study detected a significant difference in nutrient digestibility between UPR and PR $(p<0.05)$. The undigested rice in the feces of UPR was amount to $12.0 \%$, whereas no undigested rice was observed in the PR group. This clearly indicates how the two groups are different in terms of their digestibility in sheep digestive tract (Fig. 2). Similarly, NARO [7] indicated that indigestible components in the feces of crushed and uncrushed rice feed were $1.0 \%$ and $39.0 \%$, respectively. The ratio of undigested (brown rice) crushed and uncrushed rice in the feces were $1.0 \%$ and $17.0 \%$, respectively. This implies that the unpolished or not mashed rice tend to increase the indigestible rice grains that comes out with feces. By analyzing the nutrient digestibility and TDN content of PR and UPR in

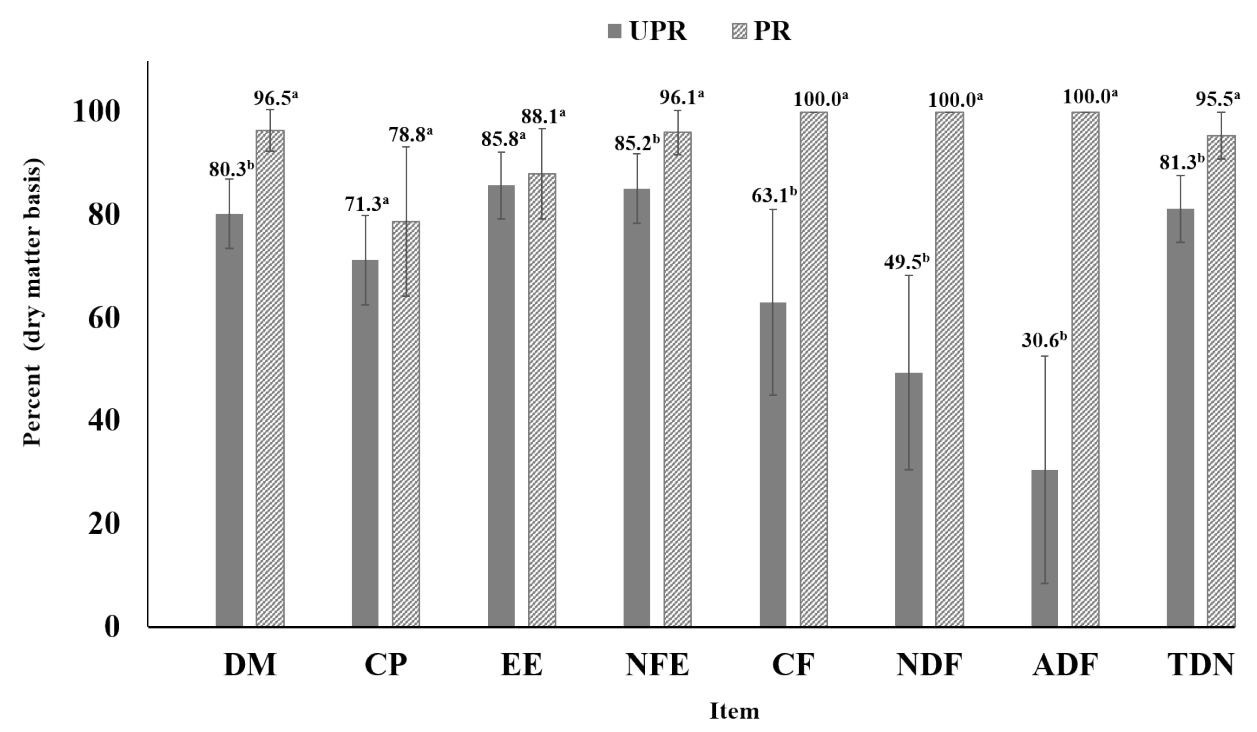

Fig. 1. Nutrients digestibility and TDN content of UPR and PR in sheep. ${ }^{a, b}$ Means in the same column with different superscripts differ $(p<0.05)$. TDN, total digestible nutrients; UPR, unpolished rice; PR, polished rice; DM, dry matter; CP, crude protein; EE, ether extracts; NFE, nitrogen free extract; CF, crude fiber; NDF, neutral detergent fiber; ADF, acid detergent fiber. 


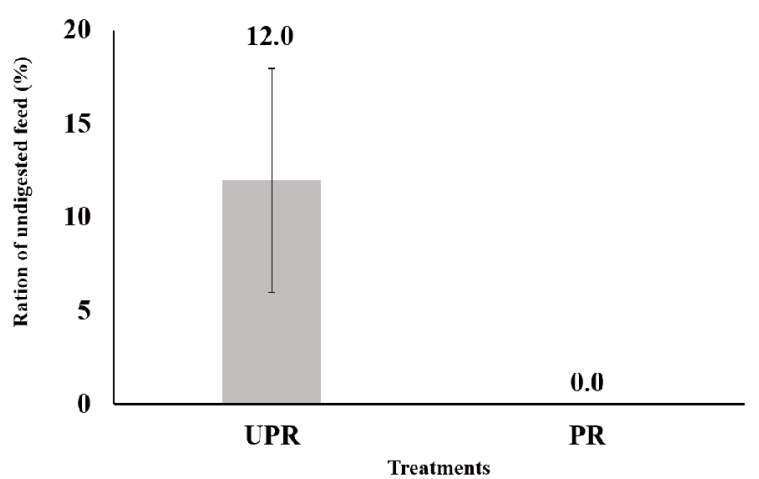

Fig. 2. Ratio of undigested experimental feed grains in feces. UPR, unpolished rice; PR, polished rice.

sheep, we have evaluated their potential to replace corn with PR in the sheep diet. According to National Livestock Research Institute [29], TDN content of corn grain were described to be $89.1 \%$. The current study presented that TDN content of UPR and PR were $81.3 \%$ and $95.5 \%$, respectively. As a result, the replacement of corn in the formulate feed with UPR and PR feed rice could be possible with the ratio of $91.2 \%$ and $100.0 \%$, respectively. The higher TDN content observed in PR is evident that it could be used as an alternative to corn grain due to surplus production that the supply could not be a problem. In the current study, the potential of rice to replace corn was evaluated through feeding sheep.

\section{Application of UPR and PR for cattle feed}

However, most of the feed industry uses rice feed to supply for cattle, which could indicate the difference between sheep and cattle in the requirement of rice feed. Therefore, we did a statistics analysis to determine the difference in nutritive value of rice feed in sheep and cattle (Table 2). No significant difference $(p>0.05)$ was observed in TDN content between sheep and cattle in both UPR and PR rice diets, but UPR showed higher tendency to be significant between sheep and cattle. This is due to the fact that, the mean difference between TDN content of UPR was higher, but the size of the sample was small and the scattering was large. It is expected that a significant difference can be expected because the standard deviation is small when the N number of UPR in-

Table 2. Comparison of TDN content of UPR and PR in sheep and cattle

\begin{tabular}{lccccc}
\hline & \multicolumn{2}{c}{ UPR } & & \multicolumn{2}{c}{ PR } \\
\cline { 2 - 3 } \cline { 5 - 6 } & Sheep & Cattle & & Sheep & Cattle \\
\hline TDN (\% of DM) & $71.9 \pm 6.7^{\mathrm{a}}$ & $80.0 \pm 6.0^{\mathrm{a}}$ & & $82.4 \pm 7.4^{\mathrm{a}}$ & $85.3 \pm 4.6^{\mathrm{a}}$ \\
$\mathrm{n}$ & 7 & 3 & & 10 & 6 \\
\hline
\end{tabular}

${ }_{\mathrm{a}, \mathrm{b}}$ Means in the same row with different superscripts differ $(p<0.05)$.

TDN, total digestible nutrients; UPR, unpolished rice; PR, polished rice; DM, dry matter. creased. This also implies that the use of UPR in sheep to the diet of cattle is less likely. However, there is a similarity in the nutritive value of PR between sheep and cattle, which suggests the applicability of the results of sheep to cattle. Therefore, the higher nutritive value observed from PR in the current study give an insight to the potential utilization of rice grains in diet of livestock. Most of the feed industry uses rice feed to supply for cattle. However, there is a limited information on the application of $\mathrm{PR}$ in the diet of sheep. Grain of brown rice was reported to be an alternative energy feedstuff that can be used in dairy cow diets, totally replacing corn grain, without any negative effect on the animal health, feed intake, digestibility, milk yield and composition [30]. As the hull part comprised of small amounts of starch and mostly non-starch polysaccharides such as cellulose and hemicellulose, dehulling is the best option to supply the optimal nutritive value for cattle.

From this study we conclude that, PR has a potential to be used to formulate the diet of cattle because of no difference nutritive value of sheep. On the other hand, UPR has known to have different nutritive value between sheep and cattle, so caution should be taken when formulating feeds for cattle.

\section{Competing interests}

No potential conflict of interest relevant to this article was reported.

\section{Funding sources}

This manuscript has not received any funding.

\section{Acknowledgements}

This manuscript has not acknowledgement.

\section{Availability of data and material}

Upon reasonable request, the datasets of this study can be available from the corresponding author.

\section{Authors' contributions}

Conceptualization: Kim JY, Sung KI.

Data curation: Kim JY, Lee BH, Chemere B, Min DH, Kim BW, Sung KI.

Formal analysis: Kim JY, Lee BH.

Project administration: Sung KI.

Resources: Sung KI.

Supervision: Sung KI.

Writing - original draft: Kim JY, Sung KI.

Writing - review \& editing: Chemere B,Lee BH, Min DH, Kim BW.

\section{Ethics approval and consent to participate}

Not applicable. 


\section{ORCID}

Ji Yung Kim

Bae Hun Lee

Befekadu Chemere

Doo Hong Min

Byong Wan Kim

Kyung Il Sung https://orcid.org/0000-0003-3515-1178

https://orcid.org/0000-0002-3811-6709

https://orcid.org/0000-0002-4449-7210

https://orcid.org/0000-0002-9404-5175

https://orcid.org/0000-0001-5047-3912

https://orcid.org/0000-0003-1232-3520

\section{References}

1. KREI [Korea Rural Economic Institute]. Agricultural outlook 2018 - II -. Naju: Korea Rural Economic Institute; 2018. p.401-21.

2. KREI [Korea Rural Economic Institute]. Rice supply imbalance, how to resolve it? - Way to reduce rice production. Naju: Korea Rural Economic Institute; 2016, November. Policy Forum Conducted at the Meeting of Seoul LWconvetion.

3. MAFRA [Ministry of Agriculture, Food and Rural Affairs]. Measure rice supply and demand long-term stability. Sejong: Ministry of Agriculture, Food and Rural Affairs; 2015.http:// www.mafra.go.kr/bbs/mafra/68/227431/download.do. Accessed 1 Sept 2016.

4. MAFRA [Ministry of Agriculture, Food and Rural Affairs]. MAFRA, Expand to 520,000 tons of rice for feed in 2017. Sejong: Ministry of Agriculture, Food and Rural Affairs; 2016. http://www.mafra.go.kr/bbs/mafra/68/228480/download.do. Accessed 16 Jan 2019.

5. MAFRA [Ministry of Agriculture, Food and Rural Affairs]. Measures to stabilize the supply and demand of rice during the harvest season of 2017. Sejong: Ministry of Agriculture, Food and Rural Affairs; 2017. http://www.mafra.go.kr/bbs/ mafra/68/229184/download.do. Accessed 16 Jan 2019.

6. Ki KS, Park SB, Lim DH, Seo S. Evaluation of the nutritional value of locally produced forages in Korea using chemical analysis and in vitro ruminal fermentation. Asian-Australas J Anim Sci. 2017;30:355-62.

7. NARO [National Agriculture and Food Research Organization]. Manual of forage rice production and utilization. Tsukuba: National Agriculture and Food Research Organization; 2015. p.122-7, 213-6.

8. Lee SM, Kang TW, Lee SJ, Ok JU, Moon YH, Lee SS. Studies on in situ and in vitro degradability, microbial growth and gas production of rice, barely and corn. J Anim Sci Technol. 2006;48;699-708.

9. Oh YK, Kim KH, Choi CW, Kang SW, Chung IB, Nho WG. Evaluation of feeding value of brown rice on Korean native beef steers (Hanwoo). J Anim Sci Technol. 2006;48;393-400.

10. McDonald P, Edwards RA, Greenhalgh JFD, Morgan CA, Sinclair LA, et al. Animal nutrition. 7th ed. Harlow: Pearson;

2010. p.237-53, 541-62.

11. Cannas A, Tedeschi L, Atzori AS, Fox DG. Prediction of energy requirements for growing sheep with the cornell net carbohydrate and protein system. In: Dijkstra J, editor. Modeling nutrient utilization in farm animals. Cambridge, MA:CABI Publishing; 2006. p.99-113.

12. Jayanegara A, Ridle M, Nahrowim, Laconi EB. Estimation and validation of total digestible nutrient values of forage and concentrate feedstuffs. IOP Conf Ser Mater Sci Eng. 2019;546:042016.

13. NRC [National Research Council]. Nutrient requirements of sheep sixth revised edition. Washington, DC: National Academy Press; 1985. p.64.

14. AOAC [Association of Official Analytical Chemists]. Official methods of analysis. 15th ed. Washington, DC: Association of Official Analytical Chemists; 1990.

15. Goering HK, Van Soest PJ. Forage fiber analysis (apparatus reagents, procedures and some applications). Washington, DC: Agricultural Research Service, United States Department of Agriculture; 1979. Agriculture Handbook No. 379.

16. NRC [National Research Council]. Nutrient requirements of dairy cattle. 6th rev. ed. Washington, DC: National Academy Press; 1989. p.9, 104.

17. Han, IK. Animal feed science. Seoul: Seonjinmunhwasa; 1995. p.345.

18. Korea Feed Information Center. Korean tables of feed composition. Seoul: Seoul National University/Korea Feed Information Center; 1982.p.272.

19. NRC [National Research Council]. Nutrient requirements of dairy cattle. 3rd ed. Washington, DC: National Academy Press; 1966. p.31.

20. NRC [National Research Council]. Nutrient requirements of dairy cattle. 5th rev. ed. Washington, DC: National Academy Press; 1978. p.46.

21. NRC [National Research Council]. Nutrient requirements of sheep. 3rd rev. ed. Washington, DC: National Academy Press; 1964. p.64.

22. NRC [National Research Council]. Nutrient requirements of sheep. 5th rev. ed. Washington, DC: National Academy Press; 1975.p.60.

23. NRC [National Research Council]. Nutrient requirements of sheep. 6th rev. ed. Washington, DC: National Academy Press; 1985. p.64.

24. NARO [National Agriculture and Food Research Organization]. Japanese feeding standard for dairy cattle. Tokyo: Japan Livestock Industry Association; 2006. p.192.

25. Macgregor, CA. Directory of feeds and feed ingredients. 3rd ed. Fort Atkinson, WI: WD Hoard \& Sons Company; 2000. 
26. SPSS. IBM SPSS statistics 22.0. Somers, NY: IBM Corp.; 2013.

27. Charles AM. Directory of feeds \& feed ingredients (Hoard's dairyman). 3rd ed. Fort Atkinson, WI: WD Hoard \& Sons Company; 2000. p.63.

28. Averts JV, De Boever JL, Cottyn BG, De Brabander DL. Comparative digestibility of feedstuffs by sheep and cows. Anim Feed Sci Techno. 1984;12:47-56.
29. National Livestock Research Institute. Standard tables of feed composition in Korea. Suwon: Rural Development Administration; 2002. p.2-3, 62-63.

30. Scheibler RB, Schafhauser J, Rizzo FA, Nornberg JL, Vargas DP, Silva JLS, et al. Replacement of corn grain by brown rice grain in dairy cow rations: nutritional and productive effects. Anim Feed Sci Techn. 2015;208:214-9. 